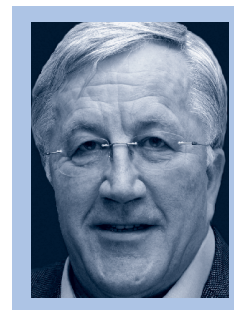

Prof. Dr. rer. nat. med. habil. Rainer Breul D.O. h.C.
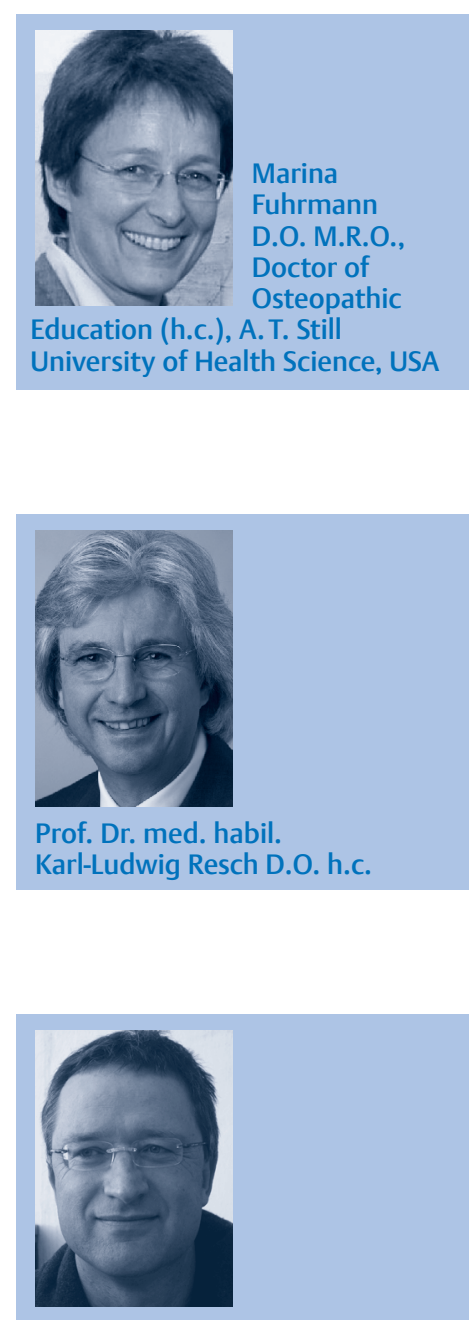

Peter Wührl D.O.

\section{Sternstunde der Osteopathie?}

W er die Schlagzeilen der osteopathischen Organe der letzten Monate Revue passieren lässt, könnte den Eindruck bekommen, Osteopathie sei in aller Munde. Staatlich anerkannte Ausbildungen wetteifern mit Schulen und Verbänden um Akademisierung. Über 70 osteopathische Institutionen saßen um einen Tisch - die Anzahl ist ebenso erstaunlich wie die Tatsache selbst. Osteopathen zeigen Flagge in der Diskussion um die H1N1-Grippe und selbst die Bundesärztekammer beehrt uns mit einem Gutachten. Die Weihnachtsbotschaft einer der führenden Schulen brachte die Stimmung auf den Punkt: „so viele, viele Begegnungen in diesem Jahr“.

Es scheint, als würde Osteopathie in der Bundesrepublik Staub aufwirbeln. Ungläubiges Staunen beschleicht nicht nur die Skeptiker. Die Akademisierungswelle zeigt sich zuallererst in einer Flut neuer Titel und in der neuen Hutmode auf osteopathischen Webseiten: Der angelsächsische Topfdeckel ist zunehmend en vogue. Die Ausbildungen bleiben Ausbildungen, jetzt aber mit Studentenausweis und akademischer Robe.

Der osteopathische Beitrag zur H1N1-Grippe bestand weitgehend in gut recherchierter, typisch heilpraktischer Impfkritik.

Ironisch gestimmte Beobachter fragten: Glauben Osteopathen daran, dass es Epidemien gibt, dass Menschen sterben? Auf Kongressen wird auf den (umstrittenen) Erfolg US-amerikanischer Osteopathen während der spanischen Grippe verwiesen. Hundert Jahre später scheinen hiesige Osteopathen nicht mal Willens, in epidemiologischen Begriffen zu denken.

Die Gutachter der Bundesärztekammer mögen einem angesichts der beschwerlichen Lektüre und Interpretation osteopathischer Textstücke leidtun. Was an ihrer Bewertung den Titel „wissenschaftlich“ verdient, ist nicht auf Anhieb zu erkennen. Möglicherweise weil es um etwas ganz anderes ging, um den Versuch der politischen Einordnung der Osteopathie im gesamtgesellschaftlichen Gesundheitssystem. Also um das, was die osteopathischen Akteure in der Diskussion um die H1N1-Epidemie versäumt haben. Eine politische Einschätzung der Osteopathie wäre zwar nötig, allerdings ist das so wissenschaftlich wie die neue akademische Hutmode akademisch.

Wenn wir diese beiden gesundheitspolitischen Ereignisse der letzten Monate nebeneinander stellen, zeigt sich eine eigentümliche Asymmetrie von gesellschaftlicher Relevanz der Themen und osteopathischer Bedeutungslosigkeit. Im Gutachten der Ärztekammer kam Osteopathie als stummer beteiligt-unbeteiligter Gegenstand zwar vor, doch zu behaupten, das Medizinverständnis der Osteopathie, ihre professionelle und gesundheitspolitische Kompetenz hätte auf dem Prüfstand gestanden, wäre übertrieben.

Ist diese Kompetenz überhaupt erkennbar: begrifflich durchdacht, institutionell verkörpert und in der Haltung der einzelnen Osteopathen wahrnehmbar? Eine berechtigte Frage, die nicht ambivalenzfrei zu beantworten ist. Osteopathie war abwesend im medizinischen und epidemiologischen Seuchendiskurs. Sie war präsent als Hysterieund Impfkritik. Ist das ihr eigentliches Wirkungsfeld?

Ginge es nicht vielmehr darum zu klären, welche institutionelle Rolle Osteopathie in einer - wie auch immer realen - Bedrohung durch eine Epidemie haben könnte? Diese Frage würde mitten ins Herz dessen führen, was Osteopathie zu einem erweiterten Medizinverständnis beizutragen hätte und welchen Ort sie im Gesundheitssystem einnehmen will. Gesundheit, in gesellschaftlichen Begriffen zu denken und ein eigenes Medizinverständnis öffentlich zu diskutieren, wäre eine Sternstunde der Osteopathie.

Die Herausgeber

Titelbild: Hinz B, et al.: Alphasmooth muscle actin expression upregulates fibroblast contractile activity, Mol Biol Cell 2001, 12: 2730-2741. Bearbeitung Pdesign, Stuttgart 2009. 